\title{
Oral health and well-being of adolescents undergoing orthodontic treatment: perspective of the adolescents and their parents/caregivers
}

\section{Salud oral y bienestar de los adolescentes que reciben tratamiento de ortodoncia: perspectiva de los adolescentes y de sus padres/cuidadores}

\section{Saúde bucal e bem-estar dos adolescentes em tratamento ortodôntico: perspectiva dos adolescentes e de seus cuidadores}

Yasmin Pissolati Mattos Bretz ${ }^{1}$

Saul Martins Paiva ${ }^{1}$ Orcid: 0000-0002-3968-1638

Lucas Guimarães Abreu ${ }^{1}$ Resarch ID: I-7369-2016

1 Universidade Federal de Minas Gerais, Faculty of Dentistry, Department of Pediatric Dentistry and Orthodontics, Belo Horizonte, Brazil.

Corresponding author

Yasmin Pissolati Mattos Bretz. Rua João Carlos, 1241, apartamento 304 - Belo Horizonte Minas Gerais, Brazil, 31030-360. Phone: (+55) (31) 99588-6548. Email: yasminpissolati@hotmail.com.

\begin{abstract}
Aim: To evaluate the oral health and well-being of adolescents with malocclusion who were submitted to orthodontic treatment, assessing the perspective of parents/caregivers and adolescents and to investigate the effects of orthodontic treatment among adolescents on the perception of oral health and well-being, in relation to the opinion of parents/caregivers and adolescents.

Methods: Adolescents between 11 and 12 years submitted to orthodontic treatment with fixed appliances at the Federal University of Minas Gerais and their parents/caregivers participated in this observational study. Adolescents and their parents/caregivers answered questions about the health of adolescents' teeth, lips, jaws and mouth and about how the condition of adolescents' teeth, lips, jaws or mouth affects adolescents overall life or well-being before orthodontic treatment onset and 12 months after fixed appliances' placement.

Results: A total of 113 pairs of adolescents and parents/caregivers participated. Parents had a significantly more negative perception of the impact of malocclusion on adolescents' lives or well-being $(p<0.001)$. Adolescents reported that their oral health improved after 12 months of
\end{abstract}


orthodontic treatment $(p<0.001)$. Adolescents also reported that their lives or well-being was significantly less affected after 12 months of orthodontic treatment $(p=0.026)$. Parents/caregivers reported that their adolescents' oral health improved after 12 months of orthodontic treatment $(p<0.001)$. Parents/caregivers also reported that their adolescents' lives or well-being was significantly less affected after 12 months of orthodontic treatment $(p<0.001)$.

Conclusion: Parents/caregivers have a more negative perception regarding the impact of malocclusion on the life and well-being of an adolescent. After 12 months of orthodontic treatment onset, parents/caregivers and adolescents considered that adolescents' overall health and well-being had improved.

Keywords: adolescent; malocclusion; orthodontic treatment; oral health; well-being.

\section{Introduction}

In the last decades, several studies on oral health-related quality of life (OHRQoL) have been found in the scientific literature. ${ }^{1}$ According to the World Health Organization (WHO), the way how oral health outcomes impact individuals' OHRQoL is an important parameter in evaluations of the Global Oral Health Program. $^{2}$ OHRQoL is a construct consisting basically of four domains: oral symptoms, functional limitations, emotional well-being and social well-being. 2,3

Similar to the evaluations among adults, OHRQoL assessments in children/adolescents are performed by means of specific and validated questionnaires. Among these questionnaires, the Child Perceptions Questionnaire (CPQ) ${ }^{4}$ and the ParentalCaregiver Perceptions Questionnaire $(\mathrm{PCPQ})^{5}$ have been used. In the first, questions aiming to evaluate the domains of OHRQoL are answered by the children/adolescents themselves. The second, in turn, is composed of questions answered by the parents/caregivers of children/adolescents. These two questionnaires also have questions that constitute the global rating, through which children/adolescents and their parents/caregivers rate the oral health of children/adolescents in general and how children/adolescents and their parents/caregivers think that the oral condition of the young individual affects his/her life or well-being in a general way. ${ }^{4,5}$

Studies with the CPQ and PCPQ show that malocclusion has a negative impact on the OHRQoL of adolescents. ${ }^{6,7,8}$ The more severe the malocclusion, the more negative is the individual's perception of his/her OHRQoL. ${ }^{9}$ The negative repercussions usually take place over the adolescent's emotional and social well-beings. ${ }^{10}$ Orthodontic treatment, on the other hand, improves function (chewing, for instance) $)^{11}$ and also enhances the OHRQoL of the individual in the emotional and social dimensions. ${ }^{12,13}$ However, studies with the global rating questions that allow us to evaluate how the adolescent with malocclusion and his/her parents/caregivers rate the oral health of this adolescent in general and how the malocclusion affects the life or well-being of this adolescent are 
still scarce in the literature. Moreover, studies evaluating the agreement between the adolescent and his/her parents/caregivers regarding the repercussions of malocclusion on adolescent's health are also sparse. ${ }^{14,15,16,17}$

Therefore, the objective of this article was two-fold: To examine the agreement between adolescents with malocclusion and their parents/caregivers regarding the evaluation of the health of adolescents' teeth, lips, jaws and mouth and their perceptions with respect to the impact of malocclusion on adolescents' lives and well-being. The hypothesis is as follows: There will be no agreement between adolescents with malocclusion and their parents/caregivers regarding the evaluation of the health of adolescents' teeth, lips, jaws and mouth and their perceptions with respect to the impact of malocclusion on adolescents' lives and well-being.. Adolescents' OHRQoL scores will be higher than parents'/caregivers' scores.

To assess the perceptions of adolescents and their parents/caregivers regarding the health of adolescents' teeth, lips, jaws and mouth and their perceptions with respect to the impact of the conditions of adolescents' teeth, lips, jaws and mouth on their lives and well-being after 12 months of orthodontic treatment with fixed appliances. The hypothesis is as follows: There will be an improvement in the perceptions of adolescents and their parents/caregivers regarding the health of adolescents' teeth, lips, jaws and mouth and their perceptions with respect to the impact of the conditions of adolescents' teeth, lips, jaws and mouth on their lives and well-being after 12 months of orthodontic treatment with fixed appliances.

\section{Materials and Methods}

\section{Sampling and setting}

The sample of this study was composed of 120 adolescents between 11 and 12 years old in the permanent dentition, who had been referred to the Dental School of the Federal University of Minas Gerais, Belo Horizonte, Brazil for orthodontic treatment with fixed appliances. Adolescents' parents/caregivers also participated. Data collection took place between October 2011 and July 2013. The inclusion criteria were as follows: the adolescent and his/her parents/caregiver should be literate in the Portuguese language. The adolescent should also need orthodontic treatment with fixed appliances. Adolescents with cognitive disorders or syndromes, individuals with a history of dental treatment in the last three months before study's commencement and those with dental caries, dental trauma and/or gingival problems during the therapy with fixed appliances were excluded. Dental caries was evaluated according to the World Health Organization (WHO). ${ }^{18}$ Dental trauma was assessed according to the Andreasen criteria. ${ }^{19}$ Gingival problems were evaluated according to the criteria of Löe. $^{20}$

\section{Ethical issues}

The study was approved by the Ethics in Research Committee of the Federal University of Minas Gerais (approval number 0421.0.203.000-11). Adolescents and parents/caregivers were informed that participation was voluntary, anonymous, 
and the refusal to participate would not preclude adolescents' orthodontic treatment. Adolescents signed a term of free and informed assent and the parents/caregivers a term of free and informed consent. At no point within the study, participants received incentives.

\section{Evaluation of global rating of oral health and well-being}

Adolescents answered two questions of the short form of the Child Perceptions Questionnaire (CPQ11-14) and parents/caregivers answered two questions of the Parental-Caregiver Perceptions Questionnaire (PCPQ) on the global rating of the adolescent's oral health and the extent to which the oral/oro-facial condition affected his/her overall life or well-being. These questionnaires were developed in Canada $^{4,5}$ and translated, cross-culturally adapted and validated in Brazil. ${ }^{7,21}$ The two questions for adolescents were: "Would you say that the health of your teeth, lips, jaws and mouth is?" e "How much does the condition of your teeth, lips, jaws or mouth affect your overall life or well-being?" The two questions for parents/caregivers were: "How would you rate the health of your child's teeth, lips, jaws and mouth?" and "How much is your child's life or wellbeing affected by the condition of his/her teeth, lips, jaws and mouth?" For the first question, adolescents and their parents/caregivers had five response options: excellent (0); very good (1); good (2); acceptable (3) and poor (4). The higher the score, the worse the evaluation of the adolescent and his/her parent/caregiver regarding the health of the adolescent's teeth, lips, jaws and mouth. For the second question, adolescents and their parents/caregivers had the following five response options: no at all (0); a little (1); somewhat (2); a lot (3) and very much (4). The higher the score, the more negative the perception of the adolescent and his/her parent/caregiver regarding the impact of the condition of the adolescent's teeth, lips, jaws or mouth on the adolescent's life or well-being. Questions were answered by the adolescents and their parents/caregivers prior to banding and fixed appliances' bonding and 12 months after adolescents' orthodontic treatment onset. During data collection, one researcher was responsible for questionnaires' administration.

\section{Malocclusion evaluation}

The Dental Aesthetic Index (DAI) was used to determine the need for orthodontic treatment among adolescents. This index consists of the analysis of 10 occlusal characteristics and assigns participants into four groups according to malocclusion severity: adolescents with mild malocclusion/slight need for treatment (DAI $\leq 25)$, adolescents with defined malocclusion, for whom orthodontic treatment is elective $(26 \leq \mathrm{DAI} \leq 30)$, adolescents with severe malocclusion, for whom orthodontic treatment is recommended $(31 \leq \mathrm{DAI} \leq 35)$ and adolescents with very severe malocclusion, for whom orthodontic treatment is mandatory (DAI $\geq 36$ ). ${ }^{22}$ After calibration, one researcher conducted the exams for malocclusion evaluation. The calibration was coordinated by a researcher with expertise in the DAI. Intra- and interexaminer agreement was calculated by means of the Kappa coefficient. The values of Kappa ranged from 0.84 to 0.90 . 


\section{Sociodemographic variables}

Information on adolescents' sex and age was collected. The monthly income was calculated as the sum of the wage of all members of the adolescents' families and was divided by the value of the Brazilian minimum wage (BZMW). At the time of the study, the BZMW corresponded to $\mathrm{R} \$$ 622.00 (US\$ 300.00). Adolescents were categorized into four groups: adolescents whose families had an income of $\leq 1$ BZMW, adolescents whose families had an income $>1$ and $\leq 3$ BZMWs, those whose families had an income of $>3$ and $\leq 5$ BZMWs and those whose families had an income $>5$ BZMWs.

\section{Statistical analysis}

The software Statistical Package for the Social Sciences (SPSS, SPSS Inc., version 22.0, Chicago, IL., EUA) was used for statistical analysis. Descriptive analysis of adolescents' sociodemographic characteristics and orthodontic treatment need was performed.

The agreement between adolescents and their parents/caregivers regarding the evaluation of the health of adolescents' teeth, lips, jaws and mouth and their perceptions with respect to the impact of the malocclusion of on their lives or well-being was assessed before banding and fixed appliances' bonding (impact of malocclusion). Directional differences for both questions were determined subtracting parents'/caregivers' global rating scores from adolescents' global rating scores. Directional differences for both questions were then compared to zero using the Wilcoxon test to assess statistical significance. To assess the magnitude of systematic bias, mean directional differences were divided by their respective standard deviations. To interpret the difference magnitude, a standardized difference of 0.2 was considered small, 0.5 was considered moderate, and 0.8 was considered large. ${ }^{23}$ The mean absolute differences for the two questions were calculated by ignoring the positive and the negative signs of the directional differences, which provide an indicator of agreement. This was then expressed as a percentage of the maximum score to assess the size of the absolute differences. The intra-class correlation coefficient (ICC) values were also calculated for the two questions. The level of agreement presented by the ICC was categorized as follows: 0.2 (poor), 02-0.4 (fair), 0.41-0.60 (moderate), 0.61-0.80 (substantial), and 0.81-1.0 (excellent). ${ }^{24}$

Comparisons of global rating assessment prior to banding and fixed appliances' bonding and 12 months after adolescents' orthodontic treatment onset were carried out for adolescents and their parents/caregivers by means of the Wilcoxon test. Statistical significance was set at $p<0.05$.

\section{Results}

Of the 120 pairs of adolescents and parents/caregivers invited to participate in the study, 113 accepted to participate and answered the questions prior to banding and bracket bonding. Twelve months after adolescents' orthodontic treatment onset, 
78 adolescents and 79 parents/caregivers answered the questions again. The reasons for losses during the follow-up were due to the non-attendance of the adolescents and/or their parents/caregivers to the adolescents' appointment on the day of the

\section{Figure 1. Study flow chard.}

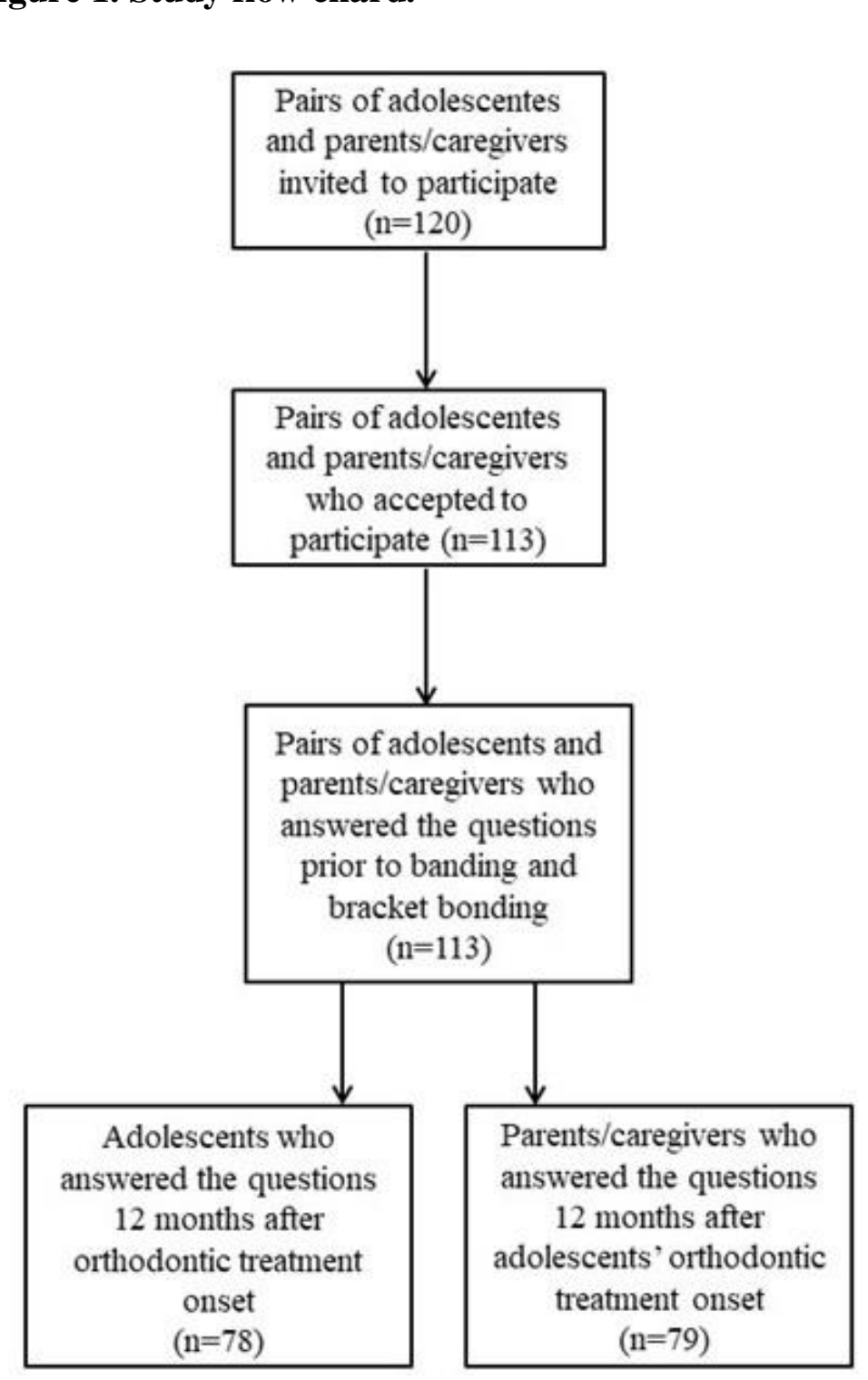

second interview. The mean age of adolescents was 11.5 years $( \pm 0.50)$. Figure 1 displays the flowchart of the study. Table 1 shows the sociodemographic characteristics and the need for orthodontic treatment of adolescents. 
Table 1: Sociodemographic characteristics and adolescents' orthodontic treatment need

\begin{tabular}{l|l}
\hline & Number $(\%)$ \\
\hline $\begin{array}{l}\text { Adolescents'sex } \\
\text { Male }\end{array}$ & $50(44.2)$ \\
Female & $63(55.8)$ \\
& \\
Family income (Brazilian minimum wage = BZMW) & \\
$\quad \leq 1$ BZMW & $19(16.8)$ \\
$>1-\leq 3$ BZMWs & $65(57.5)$ \\
$>3-\leq 5$ BZMWs & $18(15.9)$ \\
$>5$ BZMWs & $11(9.8)$ \\
& \\
Dental Aesthetic Index (DAI) & \\
$\leq 25$ & $39(34.5)$ \\
$26-30$ & $32(28.3)$ \\
$31-35$ & $26(23.0)$ \\
$\geq 36$ & $16(14.2)$ \\
\hline
\end{tabular}

Table 2 shows adolescents' and their parents'/caregivers' reports regarding the global rating of the adolescent's oral health and the extent to which malocclusion affected his/her overall well-being before banding and fixed appliances' bonding. Table 3 displays the agreement between adolescents and parents/caregivers regarding both global ratings. Compared with the adolescents (mean=1.07), parents/caregivers (mean=1.73) had a significantly more negative perception regarding the impact of the malocclusion on adolescent's life or well-being (directional difference $=0.66$, and absolute difference $=$ $1.35, p<0.001)$.

Table 2: Mean global rating and the extent to which the child is affected by malocclusion (adolescents' and parents'/caregivers' reports)

\begin{tabular}{lcccc}
\hline & Range & Adolescents Mean (SD) & Range & Parents/caregivers Mean (SD) \\
\hline Question 1* $^{*}$ & $0-4$ & $2.02(0.96)$ & $0-4$ & $2.19(0.89)$ \\
Question 2 $^{*}$ & $0-4$ & $1.07(1.00)$ & $0-4$ & $1.73(1.08)$ \\
\hline
\end{tabular}

Question 1 asks to the adolescent and parents/caregivers how they would rate the health of the adolescent's teeth, lips, jaws and mouth

Question 2 ask to the adolescent and parents/caregivers how much the adolescent's life or well-being is affected by his/her teeth, lips, jaws and mouth

${ }^{*} \mathrm{~N}=113$ pairs of adolescents and parents/caregivers

$\mathrm{SD}=$ standard deviation 
Table 3: Mean directional differences, absolute differences, and correlation analysis for mean global rating and the extent to which the adolescent is affected by malocclusion between adolescents and their parents/caregivers

\begin{tabular}{|c|c|c|c|c|c|c|c|c|c|}
\hline & \multicolumn{4}{|c|}{ Directional diferences } & \multicolumn{3}{|c|}{$\begin{array}{l}\text { Absolute } \\
\text { diferences }\end{array}$} & \multicolumn{2}{|c|}{ Correlation analysis } \\
\hline & $\begin{array}{c}\text { Mean } \\
(\mathrm{SD})\end{array}$ & $\begin{array}{c}\mathrm{CI} \\
(95 \%)\end{array}$ & $\begin{array}{c}p \\
\text { value }\end{array}$ & $\mathrm{D}$ & Mean & $\mathrm{SD}$ & $\begin{array}{c}\mathrm{S} \\
(\%)\end{array}$ & $\begin{array}{c}\mathrm{ICC}(95 \% \\
\mathrm{CI})\end{array}$ & $\begin{array}{c}p \\
\text { value }\end{array}$ \\
\hline $\begin{array}{l}\text { Question } \\
1^{*}\end{array}$ & $\begin{array}{c}0.17 \\
(1.15)\end{array}$ & $\begin{array}{c}-0.03 \\
0.39\end{array}$ & $=0.122$ & 0.14 & 0.90 & 0.74 & 22.5 & $\begin{array}{c}0.36(0.07 \\
0.55)\end{array}$ & $=0.009$ \\
\hline $\begin{array}{l}\text { Question } \\
2^{*}\end{array}$ & $\begin{array}{c}0.66 \\
(1.50)\end{array}$ & $\begin{array}{c}0.38 \\
0.94\end{array}$ & $<0.001$ & 0.44 & 1.35 & 0.93 & 23.2 & $\begin{array}{c}0.06(0.44 \\
0.22)\end{array}$ & $=0.663$ \\
\hline
\end{tabular}

Question 1 asks to the adolescent and parents/caregivers how they would rate the health of the adolescent's teeth, lips, jaws and mouth

Question 2 ask to the adolescent and parents/caregivers how much the adolescent's life or well-being is affected by his/her teeth, lips, jaws and mouth * $\mathrm{N}=113$ pairs of adolescents and parents/caregivers $\mathrm{SD}=$ standard deviation; $\mathrm{CI}=$ confidence interval; $\mathrm{D}$, Standardized difference 5 mean directional difference/standard deviation of directional difference; $\mathrm{S}$, size of the absolute difference

Table 4: Comparison of global rating of the adolescents' health before and 12 months after banding and fixed appliance bonding (adolescents' report)

\begin{tabular}{lccccc}
\hline & \multicolumn{2}{c}{$\begin{array}{c}\text { Before fixed appliance } \\
\text { bonding }\end{array}$} & \multicolumn{2}{c}{$\begin{array}{c}\text { months after fixed } \\
\text { appliance bonding }\end{array}$} & p value \\
\cline { 2 - 6 } & $\begin{array}{c}\text { Median } \\
\text { (Mean) }\end{array}$ & $\begin{array}{c}\text { Interval } \\
\text { Interquartil }\end{array}$ & $\begin{array}{c}\text { Median } \\
\text { (Mean) }\end{array}$ & $\begin{array}{c}\text { Interval } \\
\text { Interquartil }\end{array}$ & \\
\cline { 2 - 6 } Question 1 $^{* *}$ & $2.00(1.97)$ & $1.00-3.00$ & $1.00(1.47)$ & $1.00-2.00$ & $<0.001$ \\
Question 2 $^{* *}$ & $1.00(1.09)$ & $0.00-1.00$ & $1.00(0.81)$ & $0.00-1.00$ & $=0.026$ \\
\hline
\end{tabular}

Question $1=$ Would you say that the health of your teeth, lips, jaws and mouth is?

Question 2 = How much does the condition of your teeth lips, jaws or mouth affect your life or well-being overall?

*Wilcoxon test. Significant at $p<0.05$

${ }^{* *} \mathrm{~N}=78$ adolescents 
Table 4 shows the comparison of adolescents' global rating of the adolescent's health before and 12 months after banding and fixed appliances' bonding. Adolescents reported that the health of their teeth, lips, mouth and jaws significantly improved after 12 months of orthodontic treatment with fixed appliances $(p<0.001)$. Adolescents also reported that their overall lives or well-being was significantly less affected by the condition of their teeth lips, jaws or mouth after 12 months of orthodontic treatment with fixed appliances $(p=0.026)$.
Table 5 demonstrates the comparison of parents'/caregivers' global rating of the adolescent's health before and 12 months after banding and fixed appliances' bonding. Parents/caregivers reported that the health of their adolescents' teeth, lips, mouth and jaws significantly improved after 12 months of orthodontic treatment with fixed appliances $\quad(p<0.001)$. Parents/caregivers also reported that their adolescents' overall lives or well-being was significantly less affected by the condition of their teeth lips, jaws or mouth after 12 months of orthodontic treatment with fixed appliances $(p<0.001)$.

\section{Table 5: Comparison of global rating of the adolescents' health before and 12 months after banding and fixed appliance bonding (parents/caregivers report)}

\begin{tabular}{cccccc}
\hline & \multicolumn{2}{l}{ Before fixed appliance bonding } & 12 months after fixed appliance & $\begin{array}{c}p \\
\text { bonding }\end{array}$ & value $^{*}$ \\
\cline { 2 - 6 } & $\begin{array}{c}\text { Median } \\
\text { (Mean) }\end{array}$ & $\begin{array}{c}\text { Interval } \\
\text { Interquartil }\end{array}$ & $\begin{array}{c}\text { Median } \\
(\text { Mean })\end{array}$ & $\begin{array}{c}\text { Interval } \\
\text { Interquartil }\end{array}$ & \\
\cline { 2 - 6 } & $2.00(2.10)$ & $1.00-3.00$ & $2.00(1.66)$ & $1.00-2.00$ & $<0.001$ \\
$\begin{array}{c}\text { Question } \\
1^{* * *} \\
\begin{array}{c}\text { Question } \\
2^{* * *}\end{array}\end{array}$ & $2.00(1.73)$ & $1.00-3.00$ & $1.00(0.90)$ & $0.00-1.00$ & $<0.001$ \\
\hline
\end{tabular}

Question 1 = How would you rate the health of your adolescent's teeth, lips, jaws and mouth?

Question 2 = How much is your adolescent's overall life or wellbeing affected by the condition of his/her teeth lips, jaws or mouth?

${ }^{*}$ Wilcoxon test. Significant at $p<0.05$

** $\mathrm{N}=79$ parents/caregivers

The power of the study was calculated using the Power and sample Size Calculation Program (PS, version 3.0, Nashville, USA). For sample power calculation, information on question 1 before fixed appliance bonding and 12 months after fixed appliance bonding for adolescents and their parents/caregivers was used. For adolescents, the difference in the mean between the score before fixed appliance bonding and the score 12 months after fixed appliance bonding was 0.50 . The pooled standard deviation was 0.93 . The number of adolescents was 78 and type I error was 0.05 . Therefore, the power of the study was $99 \%$. For parents/caregivers, the difference in the mean between the score before fixed appliance bonding and the score 12 months after fixed appliance bonding was 0.44 . The pooled standard 
deviation was 0.90. The number of parents/caregivers was 79 and type I error was 0.05 . Therefore, the power of the study was $98 \%$.

\section{Discussion}

The present study evaluated the general health of the adolescent and how the oral and orofacial condition affects his/her life and well-being, from the perspective of the adolescents themselves and from the perspective of their parents/caregivers. The scores of parents/caregivers were higher than those of the adolescents. There is a sharp contrast between the result presented herein and our hypothesis through which we had stated that adolescents would have higher scores compared with their parents/caregivers. Thus, it is suggested that parents/caregivers are more bothered by the impact that malocclusion generates on the general life or well-being of their sons/daughters than the adolescents themselves. After 12 months of orthodontic treatment onset, adolescents and parents/caregivers considered that the life and general well-being of adolescents had improved.

The results of this study are in agreement with the results of other studies found in the literature, in which the perception of parents/caregivers on the malocclusion of adolescents was evaluated. ${ }^{25,26}$ This negative perception is mainly based on the clinical characteristics of the position of the teeth. Tooth misalignment and crowding of teeth disturbs not only adolescents, but also their parents/caregivers. ${ }^{27,28}$ Malocclusion in adolescents can lead to family problems, involving the feeling of guilt and irritation on the part of parents/caregivers, since they feel responsible for the deteriorated oral health of their sons/daughters. Disagreements among family members may also take..$^{29,30,31}$

This negative perception makes parents/caregivers think that they need to worry and make decisions about their adolescents' oral health. ${ }^{32}$ However, another study demonstrates a small percentage of parents/caregivers who are concerned with adolescents' regular visits to the dentist. ${ }^{33}$ During the consultations, the clinician must provide guidance to show to parents/caregivers, demonstrating to these individuals show to parents/caregivers their essential role for the success of the adolescent's dental treatment. Parents/caregiver are also the main decision makers with respect to the health of the young individual. Therefore, parents/caregivers can assist the adolescent in the oral health care at home, based on the guidelines and recommendations given by the dentist with respect to tooth-brushing, flossing and diet. ${ }^{34,35}$

The literature has several studies that discuss the role of orthodontic treatment in improving the well-being of adolescents. $^{36,37,38}$ This is due to the psychosocial impact of dentofacial aesthetics on the life of an adolescent and the impairment of functions caused by severe dento-skeletal discrepancies. ${ }^{39}$ The correction of malocclusion by means of orthodontic treatment contributes to increase the patient's self-esteem, directly benefiting his/her mental and psychological health. ${ }^{40}$ However, during orthodontic treatment, the adolescent may encounter adversity, such as pain and chewing 
impairment. These factors associated with the lack of guidelines/recommendations of the orthodontist may culminate in the discontinuation of treatment by the adolescent $^{11}$. Given the benefits to the adolescent's well-being and the negative impact of malocclusion, ${ }^{9,12,13}$ the practitioner should advise parents/guardians on the importance of starting treatment for malocclusion in the early stages and explain to the patient and to his/her parent/caregiver that even though possible inconveniences on the course of treatment may take place, the adolescent undergoing fixed appliance therapy is paving the way towards a better appearance and improved aesthetics. ${ }^{41}$

It is important to recognize the limitations of this study. Ideally, the orthodontic treatment should have been carried out by the same orthodontist. Herein, residents in the Orthodontic Program of the Federal University of Minas Gerais conducted the treatments. Therefore, differences in the orthodontic skills among residents should have had influence on the results.

\section{Conclusion}

In comparison to the adolescent himself/herself, parents/caregivers have a more negative perception regarding the impact of malocclusion on the life and wellbeing of an adolescent. After 12 months of orthodontic treatment onset, parents/caregivers and adolescents considered that the adolescent's overall health and well-being had improved.

\section{Acknowledgements}

Support from FAPEMIG, CAPES, CNPq and Pró-Reitoria de Pesquisa da Universidade Federal de Minas Gerais (PRPq/UFMG) is acknowledged.

\section{References}

1. Ni Riordain R, McCreary C. The use of quality of life measures in oral medicine: a review of the literature. Oral Dis 2010;16(5):419430.

2. Sischo L, Broder HL. Oral healthrelated quality of life: what, why, how, and future implications. J Dent Res 2011;90(11):1264-1270.

3. Merdad L, El-Housseiny AA. Do children's previous dental experience and fear affect their perceived oral health-related quality of life (OHRQoL)?. BMC Oral Health 2017;17(1):47.

4. Jokovic A, Locker D, Guyatt G. Short forms of the Child Perceptions Questionnaire for 1114-year-old children (CPQ11-14): development and initial evaluation. Health Qual Life Outcomes 2006;4:4.

5. Jokovic A, Locker D, Stephens M, Kenny D, Tompson B, Guyatt G. Measuring parental perceptions of child oral health-related quality of life. J Public Health Dent 2003;63(2):67-72.

6. Barbosa TS, Gaviao MB, Leme MS, Castelo PM. Oral Health-related Quality of Life in Children and Preadolescents with Caries, Malocclusions or 
Temporomandibular Disorders.

Oral Health Prev Dent 2016;14(5):389.

7. Goursand D, Paiva SM, Zarzar PM, Pordeus IA, Grochowski R, Allison PJ. Measuring parental-caregiver perceptions of child oral healthrelated quality of life: psychometric properties of the Brazilian version of the P-CPQ. Braz Dent J 2009;20(2):169-174.

8. Abreu LG, Melgaco CA, Abreu MH, Lages EM, Paiva SM. Perceptions of parents and caregivers regarding the impact of malocclusion on adolescents' quality of life: a cross-sectional study. Dental Press J Orthod 2016;21(6):74-81.

9. Sun L, Wong HM, McGrath CP. Relationship Between the Severity of Malocclusion and Oral Health Related Quality Of Life: A Systematic Review and Metaanalysis. Oral Health Prev Dent 2017;15(6):503-517.

10. Da Rosa GN, Del Fabro JP, Tomazoni F, Tuchtenhagen S, Alves LS, Anderghi TM. Association of malocclusion, happines, and oral health-related quality of life (OHRQoL) in schoolchildren. J Public Health Dent 2016;76(2):85-90.

11. Bretz, YPM, Paiva SM, Lages BEM, Abreu LG. Perceptions of pain levels and chewing impairment among adolescents undergoing orthodontic treatment with fixed appliances. J Oral Res 2018;7(3):102-107.

12. Jamilian A, Kiaee B, Sanayei S, Khosravi S, Perillo L. Orthodontic
Treatment of Malocclusion and its Impact on Health-Related Quality of Life. Open Dent J 2016;10:236241.

13. Javidi H, Vetorre M, Benson PE. Does orthodontic treatment before the age of 18 years improve oral health-related quality of life A systematic review and metaanalysis. Am J Orthod Dentofacial Orthop 2017;151(4):644-655.

14. Lawal FB. Global self-rating of oral health as summary tool for oral health evaluation in low-resource settings. J Int Soc Prec Community Dent 2015;5:S1-S6.

15. Kamper SK, Maher CG, Mackay G. Global rating of change scales: a review of strengths and weaknesses and considerations for design. $\mathrm{J}$ Man Manip Ther 2009;17(3):163170.

16. Abreu LG, Lages EM, Abreu MH, Pereira LJ, Paiva SM. Preadolescent's oral health-related quality of life during the first month of fixed orthodontic appliance therapy. J Orthod 2013;40(3):218224.

17. Abreu LG, Melgaço CA, Lages EM, Abreu MH, Paiva SM. Effect or year one orthodontic treatment on the quality of life of adolescents, assessed by the short form of the Child Perceptions Questionnaire. Eur Arch Paediatr Dent 2014;15(6):435-441.

18. World Health Organization.Oral Health Surveys:Basic Methods. $4^{\text {th }}$ ed. Geneva:World Health Organization;1997.

19. Andreasen JO, Andreasen FM, Andersson L. Textbook and Color 
Atlas of Traumatic Injuries to the Teeth. $4^{\text {th }}$ ed. Copenhagen: Blackwell Munskgaard;2007.

20. Loe H. The gingival index, the plaque index and the retention index systems.J Periodontol.1967;38(6 Suppl):610-616.

21. Torres CS, Paiva SM, Vale MP, Pordeus IA, Ramos-Jorge ML, Oliverai AC, Allison PJ. Psychometric properties of the Brazilian version of the Child Perceptions Questionnaire (CPQ1114) - short forms. Health Qual Life Outcomes 2009;7:43.

22. Jenny J, Cons NC. Establishing malocclusion severity levels on the Dental Aesthetic Index (DAI) scale. Aust Dent J 1996;41(1):43-46.

23. Cohen J. Statistical Power Analysis for the Behavioural Sciences. 2nd ed. Hillsdale, NJ: Lawrence Erlbaum and Associates; 1988.

24. Landis JR, Koch GG. The measurement of observer agreement for categorical data. Biometrics. 1977;33:159-174.

25. Scalioni F, Carrada CF, Abreu L, Ribeiro RA, Paiva SM. Perceptions of parents/caregivers on the oral health of children/adolescents with Down syndrome. Spec Care Dentist.2018;38(6):382-390.

26. Perazzo MF, Gomes MC, Neves ET, Martins CC, Paiva SM, Costa EMMB, Granville-Garcia AF. Oral problems and quality of life of preschool: self-reports of children and perception of parents/caregivers. Eur J Oral Sci.2017;125(4):272-279.

27. Talekar BS, Rozier RG, Slade GD, Ennett ST. Parental perceptions of their preschool-aged children`s oral health. J Am Dent Assoc.2005;136(3):364-372.

28. Piovesan C, Marquezan M, Kramer PF, Bonecker M, Ardenghi TM. Socioeconomic and clinical factors associated with caregivers' perceptions of children's oral health in Brazil.Community Dent Oral Epidemiol.2011;39(3):260-267.

29. Abanto J, Carvalho TS, Mendes FM, Wanderley MT, Bonecker M, Raggio DP. Impact of oral diseases and disorders on oral health-related quality of life of preschool children. Community Dent Oral Epidemiol.2011;39(2):105-114.

30. Firmino RT, Gomes MC, VieiraAndrade RG, Martins CC, Paiva SM, Granville-Garcia AF. Casecontrol study examining the impact of oral health problems on the quality of life of the families of preschoolers. Braz Oral Res.2016;30(1):121.

31. Gomes MC, Clementino MA, Pinto-Sarcamento TC, Martins CC, Granville-Garcia AF, Paiva SM. Association between parental guilt and oral health problems in preschool children: a hierarchical approach. BMC Public Health.2014;14:854.

32. Amin MS, Harrison RL, Weinstein P. A qualitative look at parents' experience of their child's dental general anaesthesia. Int $\mathrm{J}$ Paediatr Dent.2006;16(5):309-319.

33. Kramer PF, Feldens CA, Ferreira $\mathrm{SH}$, Bervian J, Rodrigues PH, Peres MA. Exploring the impact of oral diseases and disorders on quality of life of preschool children. 

Community
Dent
Oral
Epidemiol.2013;41(4):327-335.

34. Lima CM, Palha PF, Zanetii ML, Parada CM. Experiences of Family members regarding the oral health care of children. Rev Lat Enfermagem.2011;19(1):171-178.

35. Mouradian WE. The face pf child: children's oral health and dental education. J Dent Educ.2001;65(9):821-831.

36. Flores-Mir C, Brandelli J, PachecoPereira C. Patient satisfaction and quality of life status after 2 treatment modalities: Invisalign and conventional fixed appliances. Am J Orthod Dentofacial Orthop.2018;154(5):639-644.

37. Ferrando-Magraner E, Garcia-Sanz V, Bellot-Arcis C, MontielCompany JM, Almerich-Silla JM, Paredes-Gallardo V. Oral healthrelated quality of life of adolescents after orthodontic treatment. A systematic review. J Clin Exp Dent.2019;11(2):194-202.

38. Kunz F, Platte P, Keb S. Orthodontic treatment need and quality of life: Correlation between oral-health related quality of life and orthodontic treatment need in children and adolescents - a prospective interdisciplinary multicenter cohort study. Br Dent J.2018;225(9):866.

39. Deng X, Wang YJ, Deng F, Liu PL, $\mathrm{Wu}$ Y. Psychological well-being, dental esthetics, and psychosocial impacts in adolescents orthodontic patients: A prospective longitudinal study. Am J Orthod Dentofacial Orthop.2018;153(1):87-96.
40. De Couto Nascimento V, de Castro Ferreira Conti AC, de Almeida Cardoso M, Valarelli DP, de Almeoda-Pedrin RR. Impact of orthodontic treatment on selfesteem and quality of life of adult patients requiring oral rehabilitation. Angle Orthod.2016;86(5):839-845.

41. Zhang M, McGrath C, Hagg U. Changes in oral health-related quality of life during fixed orthodontic appliance therapy. Am J Orthod Dentofacial Orthop. 2008;133(1):25-29. 